energy, the fourth international congress on physical optics, and the second international congress on acoustics.

Recent developments affecting the scientific community discussed in the first part of the director's report include the surveys of the scientific potential of the United States, in which the Foundation's Office of Special Studies has participated; science and scientific man-power in the U.S.S.R. ; and the work of the National Committee for the Development of Scientists and Engineers formed by the President on April 3, 1956, which has already formed two working groups, one to expand the supply of qualified technicians and the other to promote long-term improvements in the teaching of science and mathematics in elementary and secondary schools. Besides a note on activities in the International Geophysical Year, reference is made to attempts to overcome difficulties in recruiting and retaining scientific personnel in Government service, and to the action taken to implement the recommendations of the Foundation's Speciai Commission for Rubber Research, appointed to recommend what future Federal sup. port, if any, should be given to research on synthetic rubber and the course to be followed with regard to the Government laboratories at Akra. An Advisory Panel for High Polymer Research was appointed in February 1956.

\section{THE OBSERVATORY OF HAUTE-PROVENCE}

$\mathrm{T}$

HE Observatoire de Haute-Provence, which is $2 \frac{1}{2}$ kilometres from the village of Saint-Michel, stands in grounds about 100 hectares in area which were acquired at the end of 1937. Building commenced in 1938 and was well advanced when the Second World War broke out; although this and the German occupation of France were responsible for considerable diminution of the work, it was never completely interrupted and since 1947 has been normal. The site was chosen because of its low cloudiness and it was found that the quality of images was practically independent of the height between 600 and 1,100 metres. Previous tests extending over twelve years with an $81-\mathrm{cm}$. telescope lent by Mme. Dina-Britt, at the Observatory of Paris, and provisionally installed at Forcalquier, close to the selected site, showed that for photographic, photometric and spectroscopic work this district was capable of providing excellent results. An additional advantage was found in the facility for transport from other parts of France to Saint-Michel.

The Observatory is under the control of the Centre National de la Recherche Scientifique, and in principle it is open to all French astronomers (and eventually to other astronomers who are engaged in research in astrophysics). It occupies a plateau covered for the greater part with stunted oaks at an altitude of about 650 metres, and tests showed that this is free from local disturbances. Visiting astronomers, after carrying out research there for a few weeks, are free to study the results at leisure in their own establishments, but all photographs, spectrograms and other records remain the property of the Observatory, to which they must eventually be returned. Thus the Haute-Provence Observatory participates in a most efficient manner in the general progress of astronomy, contributing to the activity of all the French observatories. The history, organization, work and equipment of the Observatory are described in a booklet* recently published by the Centre National de la Recherche Scientifique.

The isolation of the Observatory requires that a large part of its personnel should live near by, and ample arrangements have been made for this as well as for those who come to carry out research. This is fully described under "Habitations et Installations Diverses", and a plan of the grounds with positions of the equipment, workshops, etc., appears on p. 10 . There are twenty-one excellent plates showing the 120 -cm. telescope, its dome, the dome of the $193-\mathrm{cm}$. telescope which will be in use this year, the spectrograph in the electronics room, mounted on the $120-\mathrm{cm}$. telescope, and other equipment, as well as photographs of M 13, the spiral nebula in Coma, the central parts of M 31 , the Great Nebula in Orion, II 8 photographed by isolating the red $\mathrm{H} \alpha$ line of hydrogen, the nebulæ NGC 5194 and M 81 and the central region of the Milky Way photographed in blue light and also in infra-red.

The director of the Observatory is Prof. Jean Dufay, director of the Lyons Observatory, and the assistant director is Prof. M. Fehrenbach, director of the Observatory of Marseilles. M. Davidson

* Observatoire de Haute-Provence. Pp. 23+21 figures. (Paris : Centre National de la Recherche Scientifique, 1956.) 600 francs.

\section{VEGETATION AFTER FIRE}

$T$

HE responses of herbaceous vegetation to fire have been the subject of observations by J. R. Sweeney (Univ. Calif. Publ. Bot., 28, No. 4, 143 ; 1956). The author points out that, in the chaparral regions of Califormia, fires are frequent, the same areas being liable to periodic reburning. A conspicuous result is the seemingly sudden abundant appearance of plants not previously evident-sometimes described as 'burn' species. The floristic changes in these areas present many problems of interest to the botanist. As a result of detailed study of some ten burnt areas, which are described and illustrated in this memoir, the author has reached the following conclusions.

The vast majority of plant seedlings occurring on burns are from viable seeds present in the soil before the occurrence of fire. The dispersal of seeds on to burnt areas from plants present on adjacent sites does not contribute materially to the herbaceous cover. An important factor in the situation is that soil acts as an effective insulator against heat penetration. Thus the temperatures produced during fires at $\frac{1}{2}$ in. and 1 in. levels below the soil surface are generally lower than the upper limits of heat tolerance of air-dry seeds. The moisture content of seeds is correlated with heat tolerance. The marked population-changes during the first, second and third years on burns are attributable to differences in germination behaviour of seeds of different species and to the action of fire in stimulating germination and providing suitable habitat conditions for growth. The striking fluctuations exhibited by species with refractory seeds are apparently not due to the effects of ash on germination behaviour, inhibiting sub- 